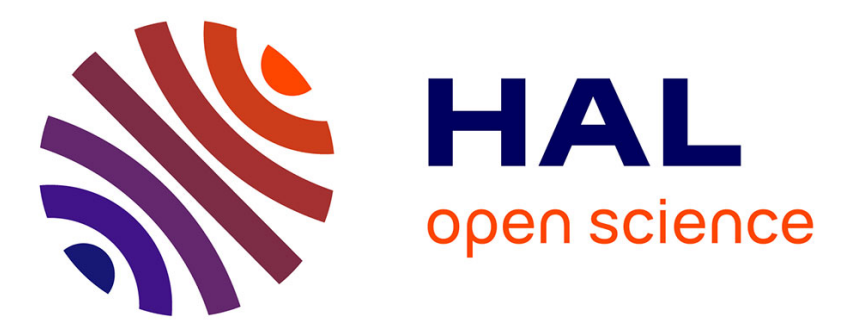

\title{
Migrating Birds Stop over Longer than Usually Thought: An Improved Capture-Recapture Analysis
}

Michael Schaub, Roger Pradel, Lukas Jenni, Jean-Dominique Lebreton

\section{To cite this version:}

Michael Schaub, Roger Pradel, Lukas Jenni, Jean-Dominique Lebreton. Migrating Birds Stop over Longer than Usually Thought: An Improved Capture-Recapture Analysis. Ecology, 2001, 82 (3), pp.852 - 859. 10.1890/0012-9658(2001)082[0852:MBSOLT]2.0.CO;2 . hal-02126401

\section{HAL Id: hal-02126401 https://hal.science/hal-02126401}

Submitted on 11 May 2019

HAL is a multi-disciplinary open access archive for the deposit and dissemination of scientific research documents, whether they are published or not. The documents may come from teaching and research institutions in France or abroad, or from public or private research centers.
L'archive ouverte pluridisciplinaire HAL, est destinée au dépôt et à la diffusion de documents scientifiques de niveau recherche, publiés ou non, émanant des établissements d'enseignement et de recherche français ou étrangers, des laboratoires publics ou privés. 


\title{
MIGRATING BIRDS STOP OVER LONGER THAN USUALLY THOUGHT: AN IMPROVED CAPTURE-RECAPTURE ANALYSIS
}

\author{
Michael Schaub, ${ }^{1,3,4}$ Roger Pradel, ${ }^{2}$ Lukas Jenni, ${ }^{1}$ And Jean-Dominique Lebreton ${ }^{2}$ \\ ${ }^{1}$ Swiss Ornithological Institute, 6204 Sempach, Switzerland \\ ${ }^{2}$ Centre d'Ecologie fonctionnelle et Evolutive/Centre National de la Recherche Scientifique (CEFE/CNRS), \\ BP 5051, 34293 Montpellier Cedex 5, France \\ ${ }^{3}$ Zoological Institute, University Zürich, Winterthurerstr. 190, 8057 Zürich, Switzerland
}

\begin{abstract}
Migrating animals often divide their journey into alternating phases of migration bouts and stopping over. For investigating many questions of migration ecology it is crucial (1) to estimate the duration of stopover phases, and (2) to test whether animals of different groups differ in their stopover behavior. Using recent advances in capturerecapture statistics, we show how total stopover duration can be estimated from capturerecapture data. The probabilities of immigration are estimated and modeled by recruitment analysis and are converted into the time the animals spent at the stopover place before capture; the probabilities of emigration are estimated and modeled by survival analysis and are converted into the time the animals spent at the stopover place after capture. The sum of the two parts is the total stopover duration. Tests for differences between groups can be addressed by an appropriate model selection procedure. Two examples of migrating passerine birds at a stopover site in Switzerland illustrate this method. Mean total stopover duration was $12.3 \mathrm{~d}$ for Reed Warblers and $7.1 \mathrm{~d}$ for Reed Buntings. This was considerably higher than values obtained by the minimum stopover duration estimation $(6.0$ and $4.4 \mathrm{~d}$, respectively). Because of the fundamental weaknesses of the minimum stopover duration estimation, which has been widely used in migration ecology, many findings obtained by this method need to be reconsidered.
\end{abstract}

Key words: Acrocephalus scirpaceus; capture-recapture; Cormack-Jolly-Seber model; Emberiza schoeniclus; emigration probability; immigration probability; migration; Reed Bunting; Reed Warbler; statistical estimation method; stopover duration.

\section{INTRODUCTION}

Many animals are migratory and visit a series of distinct areas, each for only a restricted time period. Only in a few cases can the animals be surveyed continuously or their entry into and exit from a particular area be controlled reliably. In most cases, the arrival at and departure from a given area are not directly observable and, hence, the duration of the stay at a given place is not known and must be estimated. This is particularly true for migrant birds that usually divide their journey between the breeding and wintering grounds into phases of flights and stopovers. Although stopover duration of a few large birds can now be measured directly in individuals tracked by satellite telemetry (e.g., Fuller et al. 1995, Kjellén et al. 1997), the actual and foreseeable size and costs of satellite transmitters are still too large to be applied to large samples of small birds. At least in the case of birds and other animals that can be marked individually, other methods will have to be used, such as the estimation from capture-mark-recapture data.

In migratory birds, stopovers are usually much longer than flight bouts. Hence, the total time for a mi-

Manuscript received 19 July 1999; revised 10 January 2000; accepted 1 March 2000.

${ }^{4}$ E-mail: michael.schaub@vogelwarte.ch gratory journey and its partitioning is mainly determined by the time spent at stopover places. Together, stopover duration and the rate of replenishing energy reserves largely determine the migration strategy of a bird (Alerstam and Lindström 1990, Alerstam and Hedenström 1998). Both parameters may be adjusted in response to various ecological factors (e.g., food availability, expected distance to and expected energy accumulation rate at the next stopover place, predation risk, weather, endogenous time program; Gwinner 1990, Richardson 1990, Lindström et al. 1994, Fransson and Weber 1997, Fransson 1998) and are among the important parameters in models of optimal migration (Alerstam and Lindström 1990, Weber and Houston 1997, Weber et al. 1998). Despite the obvious importance of stopover duration for our understanding of the ecology of migration, no methods are available that reliably estimate stopover duration from capturemark-recapture field data. This explains the serious lack of field studies relating stopover duration to ecological factors and testing models of optimal migration.

Marking birds individually with rings at stopover places provides capture-mark-recapture data that contain the information on stopover duration. An approach often used until recently is to calculate the so-called minimum stopover duration, which is the time elapsed between first and last capture (e.g., Cherry 1982, Lyons 
and Haig 1995, Morris et al. 1996). Apart from neglecting the time a bird may have spent at the stopover site before first capture and after last capture, this measure is based only on those birds caught at least twice and may not be representative of the entire population. Often, minimum stopover duration is used as a relative measure for the comparison of two or more groups of birds. However, because the time spent before first capture and after last capture, as well as capture probability, may vary among the comparison groups, this is not generally a valid approach. Minimum stopover duration is obviously not a useful correlate of total stopover duration.

A better approach is to analyze the capture-markrecapture data with Cormack-Jolly-Seber models. This method allows estimation of survival and capture probabilities separately and, based on open populations, assumes that the estimated survival probability is the probability of staying at the stopover place. Simple formulas for the calculation of stopover duration can be used when survival and capture probabilities are assumed to be constant over time (Lavee et al. 1991, Holmgren et al. 1993). Kaiser (1995) and Pradel et al. (1997b) calculated stopover duration when survival and capture probabilities vary over time. However, the estimates of survival probabilities are conditioned on capture, i.e., the time the birds spend at a stopover place after they have been captured is estimated. The time the birds spent at the stopover place before capture remains unknown.

The aim of this study was to demonstrate how stopover duration can be estimated by making use of recent advances in capture-recapture data analysis (for modeling of survival, see Lebreton et al. [1992]; for recruitment analysis, see Pradel [1996]). The total stopover duration is calculated as the sum of the time the animal spent at the place before and after capture. For an animal captured at a given occasion, the probability of being in the population before this capture (the seniority probability) is estimated by means of a recruitment analysis (Pradel 1996). The probability of being in the population after this same capture is estimated by ordinary survival analysis, assuming that true survival is one. We developed a formula for the transformation of the survival and the seniority probabilities that change over time into total stopover duration (see the Appendix). Because there are no analytical formulas for the covariances between the survival and the seniority probabilities, the confidence intervals for total stopover duration have to be calculated using some nonparametric procedure. We give a recommendation for calculating these confidence intervals. Finally, in two examples we compare the estimates of total stopover duration with stopover durations obtained by the methods used earlier, and we show that stopover duration in small passerines has generally been underestimated.

\section{Estimating Total Stopover Duration}

Animals need to be marked individually so that the individual capture histories are available as an $n \times m$ matrix, where $m$ is the number of capture events and $n$ is the number of birds caught. An element of the matrix $I_{n, m}$ is either zero (if the $n$th bird was not caught at the $m$ th event), or one (if it was caught). For this study in which birds were caught daily over two to three months, we pooled this matrix over five days, resulting in a reduced matrix with $n \times(\mathrm{m} / 5)$ dimensions. The determination of stopover duration consists of four steps: (1) goodness-of-fit test of a global model; (2) modeling of stopover duration before capture, by means of a recruitment analysis (Pradel 1996); (3) modeling of stopover duration after capture, with ordinary survival analysis (Lebreton et al. 1992); and (4) calculation of the means and variances of the total stopover duration, using the estimates and models obtained from steps two and three.

Goodness-of-fit test.-This test assesses whether a global model adequately fits the data (Lebreton et al. 1992). Goodness-of-fit tests identify, among others, the occurrence of heterogeneity of survival and capture probabilities between animals. One possible reason for the lack of fit stems from differences in capture probability between animals captured and those not captured at the previous occasion (immediate trap response models; Pradel 1993). Alternatively, the occurrence of transients (i.e., animals that stay one time unit only [transient models; Pradel et al. 1997a]) may contribute to poor fit. Transience, itself, is a biologically important phenomenon in the study of migration. For the examples that follow, we fitted the Cormack-Jolly-Seber model to both the full and pooled data sets with software REL-CR, a modified version of the software RELEASE (Burnham et al. 1987).

Modeling of stopover duration before capture.This step is termed "modeling of immigration" or "modeling of stopover duration before capture." By performing a survival analysis run backwards in time, separate estimates of the probability of having been in the population before the current capture (denoted as $\gamma$ ) and of the probability of capture $(r)$ are obtained (Pradel 1996). Technically, this can be done by reversing the capture histories and then performing a survival analysis. The probability of immigration (1 $\gamma$ ) cannot be estimated precisely if birds born during the study period add to the sample. Because migration generally does not overlap with breeding, this presented no problem in the examples that follow. Here, we calculated the estimates with the software SURGE 5 (Reboulet et al. 1999), and fitted models that had either time-dependent or constant parameter structures. Model selection followed the suggestions of Lebreton et al. (1992) and was based on the Akaike's Information Criterion (AIC) and on likelihood ratio tests between nested models. 
Modeling of stopover duration after capture.-This step is termed "modeling of emigration" or "modeling of stopover duration after capture." With a survival analysis, separate estimates of the probability of capture $(p)$ and of the probability of survival $(\phi)$ were obtained (Lebreton et al. 1992). The estimated probability of survival $\phi$ is the product of two probabilities that could only be separated by multistate models (Nichols and Kendall 1995): the true probability of survival $\left(\phi^{*}\right)$, and the probability of staying in the area $\left(\phi^{* *}\right)$, i.e., not emigrating. However, because true survival rate $\phi^{*} \approx 1$ over the rather short period of stopover of migrating birds, the estimated values $\phi$ are almost equal to the probabilities of staying in the area $\phi^{* *}$. Model selection followed the same procedures as described for the modeling of immigration.

Calculation of stopover duration from $\gamma$ and $\phi$.The total stopover duration of birds captured at occasion $i$ is the sum of the time they have stayed before capture (recruitment analysis) and the time they will stay thereafter (survival analysis). We first consider how to calculate stopover duration after $i, \mathrm{Sa}_{i}$. This is equivalent to calculating a "life expectancy in the site" from the probabilities of staying in the area estimated in the previous step. It requires two additional assumptions. First, we assume that the instantaneous rate of departure is constant within each interval. This is not a very strong assumption, and a reasonable one without indications to the contrary. The most difficult point was to decide what should be the probabilities of staying in the area beyond the study period. Note also that, if these probabilities are estimated with model $\left\{\phi_{t}\right.$, $\left.p_{t}\right\}$, the last separate estimate of $\phi$ is the one referring to the period between the last-but-two and the last-butone capture occasions, because the probability of staying during the last interperiod is confounded with the capture probability at the last occasion (Darroch 1959). For the first nonestimable $\phi$, we opted in all cases for a weighted gliding average involving the last three estimable $\phi$ 's. If there are $n$ estimable $\phi$ 's, we estimate the probability of staying one occasion beyond the study period $\phi_{n+1}$ as follows:

$$
\phi_{n+1}=\frac{\phi_{n-2}+2 \phi_{n-1}+4 \phi_{n}}{7} .
$$

Assuming $\phi_{n+1}$ as defined by Eq. 1 to be valid indefinitely after the study period, it was possible to find the formula for $\mathrm{Sa}$ (see the Appendix for derivation):

$$
\mathrm{Sa}=\sum_{i=1}^{n}\left(\prod_{j=1}^{i-1} \phi_{j}\right)\left(1-\phi_{i}\right)\left(\frac{1}{\mu_{i}}\right)+\left(\prod_{j=1}^{n} \phi_{j}\right) \frac{1}{\mu_{n+1}} .
$$

We did not find large differences in Sa $(<10 \%)$ if $\phi_{n+1}$ was chosen to be either the weighted gliding average Eq. 1, the mean of all estimable values $\phi_{\text {mean }}$, or just the last value $\phi_{n}$, if most $\phi_{i}$ were low $(<0.4)$. Because Eq. 2 for calculating $\mathrm{Sa}_{i}$ always contains $\phi_{n+1}$, all $\mathrm{Sa}_{i}$ are theoretically affected by the value chosen for $\phi_{n+1}$.
The influence of the choice of $\phi_{n+1}$ on $\mathrm{Sa}_{i}(1 \leq i \leq n)$ increases toward the end of the study period. When the probability of staying is constant during the entire study period, Eq. 2 simplifies to the mean expected lifetime equation (Seber 1982):

$$
\mathrm{Sa}=\frac{-1}{\ln \phi} .
$$

The mean stopover duration before a current capture at $i, \mathrm{Sb}_{i}$ can, of course, be estimated with the same expression. However, since the recruitment analysis is run backwards in time, the estimates of $\gamma$ are parameterized differently than those of $\phi$. If there are $n$ estimable $\phi$ and $\gamma$, the mean total stopover duration $S_{i}$ of birds captured at $i(1 \leq i \leq n)$ is the following:

$$
\begin{aligned}
S_{i}= & \sum_{k=i}^{n}\left(\prod_{j=i}^{k-1} \phi_{j}\right)\left(-\frac{1-\phi_{k}}{\ln \phi_{k}}\right)+\left(\prod_{j=i}^{n} \phi_{j}\right) \frac{-1}{\ln \phi_{n+1}} \\
& +\sum_{k=n-i+1}^{n}\left(\prod_{j=i}^{k-1} \gamma_{j}\right)\left(-\frac{1-\gamma_{k}}{\ln \gamma_{k}}\right) \\
& +\left(\prod_{j=n-i+1}^{n} \gamma_{j}\right) \frac{-1}{\ln \gamma_{n+1}} .
\end{aligned}
$$

Closed-form formulas for an approximation of the variance of total stopover duration could theoretically be found by the delta method (see, for instance, Seber [1982]). However, the values of some components in this formula, namely the covariances between the $\phi$ 's and the $\gamma$ 's, were missing. This problem could be solved if the estimates of $\phi$ and $\gamma$ were derived from independent data sets by, for instance, splitting the data set randomly in half, but this makes poor use of the data. We instead resorted to bootstrapping (Efron and Tibshirani 1993). Using nonparametric bootstrap on the individual capture histories, we obtained confidence intervals of total stopover duration in all cases. A MATLAB (Anonymous 1992) program was written that performed 10000 iterations each time. A compiled version named SODA is available (see Supplementary Material).

\section{Application to Data: Examples}

\section{The data}

In order to illustrate the method we have developed, and to demonstrate differences in estimates of stopover duration compared with earlier approaches, a typical data set originating from the study of bird migration was chosen. In a river delta in southern Switzerland (Bolle di Magadino 46 $2^{\prime} \mathrm{N}, 8^{\circ} 9^{\prime} \mathrm{E}, 661$ ha with $\sim 37$ ha covered by reeds, Phragmites australis), $486 \mathrm{~m}$ of mist nets were set during the autumn migration periods 1994-1996 in the reed bed. Catches was performed daily, with the same number of mist nets at fixed positions. All captured birds were aged (Jenni and Winkler 1994), examined for molt intensity ( $<20$ vs. $>20$ body feathers growing), marked with individual rings, and released immediately thereafter. Retraps were treat- 
TABLE 1. Selection of the most parsimonious models for the stopover duration before capture (immigration; models 1-3) and after capture (emigration; models 4-6) of the Reed Warbler.

\begin{tabular}{|c|c|c|c|c|}
\hline Model & $\mathrm{np}$ & DEV & AIC & Tests between models \\
\hline 1) $\left\{\gamma_{t}, r_{t}\right\}$ & 25 & 495.22 & 545.22 & \\
\hline 2) $\left\{\gamma_{t}, r\right\}$ & 14 & 505.00 & 533.00 & $\begin{array}{l}\text { Capture probability time dependent, } \\
\text { (1) vs. (2): } \chi_{11}^{2}=9.78, P=0.55\end{array}$ \\
\hline 3) $\{\gamma, r\}$ & 2 & 545.72 & 549.72 & $\begin{array}{l}\text { Immigration probability time dependent, } \\
\text { (2) vs. (3): } \chi_{12}^{2}=40.72, P<0.001\end{array}$ \\
\hline 4) $\left\{\phi_{t}, p_{t}\right\}$ & 25 & 528.52 & 578.52 & \\
\hline 5) $\left\{\phi_{t}, p\right\}$ & 14 & 543.38 & 571.38 & $\begin{array}{l}\text { Capture probability time dependent, } \\
\text { (4) vs. (5): } \chi_{11}^{2}=14.86, P=0.19\end{array}$ \\
\hline 6) $\{\phi, p\}$ & 2 & 552.82 & 556.82 & $\begin{array}{l}\text { Emigration probability time dependent, } \\
\text { (5) vs. (6): } \chi_{12}^{2}=9.44, P=0.67\end{array}$ \\
\hline
\end{tabular}

Notes: Notation is as follows: np, number of estimable parameters; DEV, relative deviance given by SURGE; AIC, Akaike Information Criterion. Model notation follows Lebreton et al. (1992). Boldface denotes the AIC values of the models finally selected.

ed in the same manner. We analyzed the data of all three years together.

Two species were chosen, the Reed Warbler (Acrocephalus scirpaceus) and the Reed Bunting (Emberiza schoeniclus), both inhabiting reed beds during the breeding and migration season, and breeding over most of Europe (Hagemeijer and Blair 1997). The Reed Warbler is a nocturnal long-distance migrant (Glutz von Blotzheim and Bauer 1991) that winters in tropical Africa. The Reed Bunting is a short-distance migrant that generally migrates during the day over continental Europe. Most individuals winter in the Mediterranean area or at coastal western Europe (Glutz von Blotzheim and Bauer 1997). In order to exclude most individuals belonging to the local breeding population that might not yet be on migration, we included all Reed Warblers that were caught for the first time after 14 August and all Reed Buntings caught after 13 September. Because adult and first-year birds migrate during slightly different periods, we included only first-year birds. Fur-

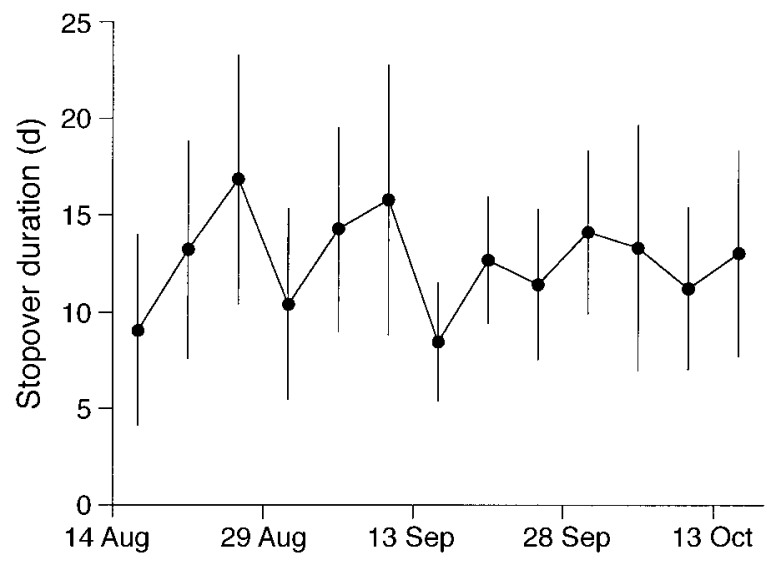

FIG. 1. Mean total stopover duration (dots) and 95\% confidence intervals (vertical lines) of first-year, nonmolting Reed Warblers present at different five-day periods during autumn migration. Estimation of total stopover duration was derived from a model with time-dependent immigration probabilities and constant emigration probability (see Table 1). thermore heavily molting Reed Warblers were excluded, because not all of them are likely to be on migration.

\section{Stopover duration of Reed Warblers}

During $70 \mathrm{~d}$ of the autumn migration period, 567 Reed Warblers were caught. Of these, 90 were recaptured once, 17 twice, and one bird three times. After pooling over five days, the number of capture occasions was reduced to 14 , and the number of retraps was reduced to 54 birds recaptured once and seven recaptured twice. The goodness-of-fit tests for the most general model (Cormack-Jolly-Seber-model) to the data set containing 70 capture days $\left(\chi_{90}^{2}=102.9, P=0.17\right)$ and to the pooled data set containing 14 capture occasions were not significant $\left(\chi_{27}^{2}=32.7, P=0.21\right)$. None of the four subtests revealed significance, which indicated that the model assumptions were reasonably met.

When modeling stopover duration before and after capture, capture probability was constant throughout the study period (Table 1 ). The immigration probability was time dependent (model 2 in Table 1), whereas the most parsimonious model for describing emigration was constant in time (model 6 in Table 1). Therefore, total stopover duration was time dependent (Fig. 1). The $95 \%$ confidence intervals were quite wide and almost symmetrical.

Minimum stopover duration was calculated as the difference in days between last and first capture plus one, because Reed Warblers are night-migrating birds and conceivably could have arrived (at the latest) the night preceding initial capture and departed (at the earliest) the night following last capture. Mean minimum stopover duration derived from the nonpooled data set was only approximately half as long as mean total stopover duration (Table 2).

\section{Stopover duration of Reed Buntings}

Of 1712 Reed Buntings caught, 47 were recaptured once, and two were recaptured twice, during $50 \mathrm{~d}$ of the autumn migration period. In the data set pooled over five days with 10 capture occasions, the number of recaptures was 35 birds recaptured once and one 
TABLE 2. Different components of stopover duration (measured in days) estimated with the new method, compared with minimum stopover duration as used in most earlier studies.

\begin{tabular}{|c|c|c|c|c|c|c|}
\hline \multirow[b]{2}{*}{ Method } & \multicolumn{3}{|c|}{ Reed Warbler } & \multicolumn{3}{|c|}{ Reed Bunting } \\
\hline & Duration $(\mathrm{d}) \dagger$ & SD & $n$ & Duration $(\mathrm{d}) \dagger$ & SD & $n$ \\
\hline \multicolumn{7}{|l|}{ New method } \\
\hline Stopover duration before capture $\ddagger$ & 6.24 & 0.84 & 567 & 3.28 & 0.79 & 1712 \\
\hline Stopover duration after capture $\S$ & 6.01 & 0.83 & 567 & 3.85 & 1.22 & 1712 \\
\hline Total stopover duration & 12.25 & 1.67 & 567 & 7.13 & 2.00 & 1712 \\
\hline Minimum stopover duration & $6.00(2-34)$ & 5.04 & 108 & $4.41(1-23)$ & 2.81 & 49 \\
\hline
\end{tabular}

Note: For the sake of comparison, stopover durations estimated with the new method were derived from the models with constant parameters $\{\phi, p\}$ and $\{\gamma, r\}$ for both species.

$\dagger$ Main entries are mean values; numbers in parentheses indicate range.

\$ Variable Sb, estimated using an equation analogous to Eq. 2 for Sa. See the Appendix for derivation.

$\S$ Variable Sa from Eq. 2. See the Appendix for derivation.

bird twice. The goodness-of-fit test to the full data set (50 capture occasions) was significant $\left(\chi_{44}^{2}=79.7, P\right.$ $<0.001)$. However, most of the deviation was due to one component in the subtest 3SR. Without this component, the overall test was not significant $\left(\chi_{43}^{2}=51.0\right.$, $P=0.19)$. In the pooled data set (10 capture occasions), neither the overall goodness-of-fit test $\left(\chi_{15}^{2}=15.3, P\right.$ $=0.43$ ) nor one of the four subtests was significant. Because of the limited nature of the problem in the full data set, and because the pooled data set had no similar problem, we considered the Cormack-Jolly-Seber model as the starting point.

As seen with the Reed Warblers, the capture probabilities for stopover duration before and after capture were constant in time for Reed Buntings (Table 3). The probability of immigration was also constant (model 3 in Table 3). Model selection for emigration was not clear. Two models (models 5 and 6 in Table 3) had almost the same AIC, and the likelihood ratio test was only slightly significant $(P=0.047)$. The simpler model had 1.128 times better support than the more complicated one, given the data (calculated from the Akaike weights; Burnham and Anderson 1998). We calculated total stopover duration for both models. If models 3 and 5 (Table 3) were used, total stopover duration was higher at the beginning of the study (Fig. 2). The 95\% confidence intervals were very wide at beginning and much narrower thereafter. Mean stopover duration derived from models 3 and 6 (Table 3) was $7.13 \mathrm{~d}$ (CI, 4.00-11.73 d).

Minimum stopover duration was calculated as the difference in days between last and first capture, because Reed Bunting are day-migrating birds and might therefore have arrived just before initial capture and might depart just after last capture. Mean minimum stopover duration derived from the nonpooled data set was $38 \%$ shorter than total stopover duration (Table 2).

\section{DISCUSSION}

\section{The new method to estimate stopover duration}

Stopover duration estimates, as proposed by this new method, are based on immigration and emigration probabilities. This requires that an area to and from which the animals immigrate and emigrate has been defined. The area that the animals cover by random movements within five days (in our examples), while still having the chance to be captured, is only crudely defined, however. If the coverage with mist nets or other traps is low, and the animals of consideration make nonrandom movements before leaving the area for another migration bout, estimated stopover duration is likely to be

TABLE 3. Selection of the most parsimonious models for the stopover duration before capture (immigration; models 1-3) and after capture (emigration; models 4-6) of the Reed Bunting.

\begin{tabular}{|c|c|c|c|c|}
\hline Model & $\mathrm{np}$ & $\mathrm{DEV}$ & $\mathrm{AIC}$ & Tests between models \\
\hline 1) $\left\{\gamma_{t}, r_{t}\right\}$ & 17 & 374.60 & 408.60 & \\
\hline 2) $\left\{\gamma_{t}, r\right\}$ & 10 & 382.65 & 402.65 & $\begin{array}{l}\text { Capture probability time-dependent, } \\
\text { (1) vs. (2): } \chi_{7}^{2}=8.05, P=0.33\end{array}$ \\
\hline 3) $\{\gamma, r\}$ & 2 & 395.29 & 399.29 & $\begin{array}{l}\text { Immigration probability time-dependent, } \\
\text { (2) vs. (3): } \chi_{8}^{2}=12.64, P=0.12\end{array}$ \\
\hline 4) $\left\{\phi_{t}, p_{t}\right\}$ & 17 & 360.58 & 394.58 & \\
\hline 5) $\left\{\phi_{t}, p\right\}$ & 10 & 367.96 & 387.96 & $\begin{array}{l}\text { Capture probability time-dependent, } \\
\text { (4) vs. (5): } \chi_{7}^{2}=7.38, P=0.39\end{array}$ \\
\hline 6) $\{\phi, p\}$ & 2 & 383.72 & 387.72 & $\begin{array}{l}\text { Emigration probability time-dependent, } \\
\text { (5) vs. (6): } \chi_{8}^{2}=15.76, P=0.05\end{array}$ \\
\hline
\end{tabular}

Notes: Notation is as follows: np, number of estimable parameters; DEV, relative deviance given by SURGE; AIC, Akaike Information Criterion. Model notation follows Lebreton et al. (1992). Boldface denotes the AIC values of the models finally selected. 


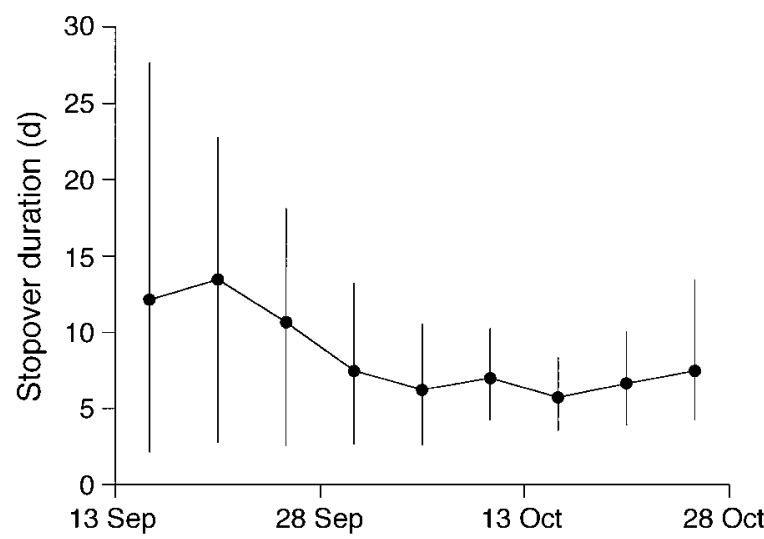

FIG. 2. Mean total stopover duration (dots) and 95\% confidence intervals (vertical lines) of first-year Reed Buntings present at different five-day periods during autumn migration. Estimation of total stopover duration was derived from a model with constant immigration probability and time-dependent emigration probabilities (see Table 2).

biased. The intensity and direction of the bias will depend on the relationship between probability of returning to the sampled area for those that were present vs. absent during the period before (Kendall et al. 1997). In contrast to Reed Warblers, Reed Buntings are known to move around a lot at a stopover place (Bastian 1992). This may explain the rather short stopover duration estimated for this species; true stopover duration might be longer. Therefore, stopover duration estimates obtained in rather small and well-defined sites (e.g., habitat islands) with a high coverage of traps will be more precise. If the site is large, the spatial distribution of the traps should be widespread in order to reduce the bias. The probability of movements within the stopover area can be estimated by multistate models (Nichols and Kendall 1995), requiring the use of at least two distinct trapping areas.

Pooling over capture occasions, as proposed for the two examples, has both disadvantages and advantages. It introduces a bias into the estimates that is a function of the capture and immigration/emigration probabilities, as well as depending on the degree of pooling (Hargrove and Borland 1994). For our examples, the bias in the immigration/emigration parameter estimates is expected to be $<1 \%$, because the degree of pooling, the daily capture probability, and the daily immigration/emigration probabilities were all rather low. Dual advantages of pooling also exist. The number of parameters to be estimated is reduced; hence identifiability problems are much less pronounced. Furthermore, the parameters are estimated with a higher precision. However, information regarding changes in the parameters during the pooling interval is lost. It depends on the emphasis of the study whether or not this is a serious lack.

\section{Possible extensions of the new method}

The proposed method has several possibilities of extension. First, it is possible to test whether different groups of animals (e.g., age or sex classes, animals in different years, fat and lean birds, molting and nonmolting birds) differ in their immigration or emigration behavior. These covariates can be included into the model selection processes and tested as to whether they influence stopover duration before and after capture (Lebreton et al. 1992). However, in some cases, the effect of such factors on total stopover duration cannot be addressed. If, for instance, a factor increases stopover duration before capture, and decreases stopover duration after capture, then one cannot be sure whether the factor has an influence on total stopover duration. Second, it can be investigated whether transients (animals that stay one day only) are present (see Methods). If there are transients at the stopover place, their proportion can be estimated, and stopover duration of nontransient birds thus calculated (Pradel et al. 1997a). However, the proportion of transients should be estimated from the nonpooled data set. Third, evidence of possible trends of stopover duration with time can be tested in the model selection procedure (Lebreton et al. 1992).

The probability of immigration $(1-\gamma)$ and emigration $(1-\phi)$ are each interesting on their own, providing insights into stopover ecology. For instance in migrating birds, influences of weather on the decision of landing and embarking could be addressed.

\section{The examples and comparison with earlier methods}

Although there were considerable differences in mean total stopover duration between Reed Warblers present at different times (range, 8.4-16.8 d), there seemed to be no overall time trend in stopover duration, and mean total stopover duration was $12.3 \mathrm{~d}$. Reasons for the fluctuating stopover duration are unclear. It is possible that weather conditions, the migration of different populations at different times, or differences between years caused this variation. Two models for the determination of total stopover duration for Reed Buntings were quite similar. However the model with the highest support, given the data, was the constant-time model. Indeed, the estimates at the beginning of the migration season obtained from the time-dependent model had very large confidence intervals. Stopover duration estimates for the Reed Warbler at the beginning of the study period are probably less reliable, because the most parsimonious model for stopover duration before capture is time dependent. Because of this dependence, the estimates at the beginning of the study period are most strongly influenced by assumed values as derived from Eq. 3. The contrary is true for the stopover duration of the Reed Bunting, if the timedependent model for emigration is considered. Here, because stopover duration after capture is time depen- 
dent, the estimates on total stopover duration at the end of the study period are probably less reliable.

Total stopover duration estimated with this new method was considerably longer than stopover durations obtained with earlier methods. Estimates of stopover durations that are based on Cormack-Jolly-Seber types of models (e.g., Lavee et al. 1991, Holmgren et al. 1993, Kaiser 1995, Pradel et al. 1997b) correctly determine the time that birds spend at the stopover place after they have been caught for the first time. However, this is not total stopover duration, and the assumption that birds that were captured for the first time are new arrivals is unrealistic for most studies. For example at the Bolle di Magadino site, the daily capture probability (providing that the bird is at the site) is $\sim 5 \%$ for Reed Warblers and $\sim 1 \%$ for Reed Buntings, respectively. Hence, $95 \%$ of all Reed Warblers and $99 \%$ of all Reed Buntings are not caught at the arrival day.

The determination of stopover duration with the minimum stopover method (e.g., Cherry 1982) has several weaknesses and can give wrong and misleading results. All captured birds may be regarded as a random sample of birds stopping over at a given site. Hence, inferences about stopover duration must be based on all birds caught, and not only on birds that are caught at least twice. Otherwise, the estimated minimum stopover duration is an estimate only for those birds that are caught at least twice. For those birds, this estimate is indeed a minimum estimate, whereas this must not be the case for the entire population. If the true stopover duration of most birds is rather low, but few birds stay a long time and these birds are caught shortly after arrival and before departure, the minimum stopover duration overestimates true stopover duration. Considering only birds that were captured at least twice has often been justified by the assumption that birds caught only once are transients (e.g., Morris et al. 1994, Lyons and Haig 1995). But given the usually low capture probabilities with mist nets, this assumption is rather unrealistic. For example, if the daily capture probability is $5 \%$, and all birds stay $10 \mathrm{~d}$, a simple binomial model predicts that $59.9 \%$ of all birds present will not be caught, $31.5 \%$ will be caught once, and $8.6 \%$ more than once. Hence $78.5 \%$ of all captured birds are captured only once, but are not transients. This effect is less severe if capture probabilities are higher. Nevertheless, even if Reed Warblers are tape lured, daily capture probability does not exceed 25\% (Schaub et al. 1999). For these reasons and those given in the Introduction, minimum stopover duration should not be used as an indication of stopover duration of the whole population and for the comparison of stopover behavior between groups. However minimum stopover duration can be helpful when a parameter (e.g., body mass change) of individual birds is related to the time they stayed at the stopover place (e.g., Lindström and Alerstam 1992, Schaub and Jenni 2000). Furthermore, it gives good results if the animals under consideration can be caught when entering and leaving a site, e.g., for migrating fishes that enter and leave a lake by a single river (e.g., Berg and Berg 1989, Shreffler et al. 1990).

The two main methods used thus far for estimating stopover duration of small passerine birds generally underestimate total stopover duration. They provide reliable estimates only for special cases: for minimum stopover duration, if capture probability is very high; and for stopover duration after capture, if almost all birds are captured at arrival. Hence, with few exceptions, conclusions thereof about migration strategies are questionable and should be reconsidered.

\section{ACKNOWLEDGMENTS}

We are greatly indebted to Roberto Lardelli for providing the ringing data, to Heinz-Ulrich Reyer and to two anonymous referees for critically reviewing earlier drafts of the manuscript, and to Remi Choquet for compiling the SOD program. M. Schaub was supported by the Swiss National Science Foundation, grant no. 3100-40568.94.

\section{Literature Cited}

Alerstam, T., and A. Hedenström. 1998. The development of bird migration theory. Journal of Avian Biology 29:343369.

Alerstam, T., and Å. Lindström. 1990. Optimal bird migration: the relative importance of time, energy, and safety. Pages 331-351 in E. Gwinner, editor. Bird migration: the physiology and ecophysiology. Springer, Berlin, Germany. Anonymous. 1992. MATLAB reference guide. MathWorks, Natick, Massachusetts, USA.

Bastian, A. 1992. Mobitität von Kleinvögeln in einem süddeutschen Rastgebiet während der Wegzugphase. Ökologie der Vögel 14:121-163.

Berg, O. K., and M. Berg. 1989. The duration of sea and freshwater residence of the sea trout, Salmo trutta, from the Vardnes River in northern Norway. Environmental Biology of Fishes 24:23-32.

Burnham, K. P., and D. R. Anderson. 1998. Model selection and inference: a practical information-theoretic approach. Springer-Verlag, New York, New York, USA.

Burnham, K. P., D. R. Anderson, G. C. White, C. Brownie, and K. H. Pollock. 1987. Design and analysis methods for fish survival experiments based on release-recapture. American Fisheries Society Monograph 5:1-437.

Cherry, J. D. 1982. Fat deposition and length of stopover of migrant White-crowned Sparrows. Auk 99:725-732.

Darroch, J. N. 1959. The multiple recapture census. II. Estimation when there is immigration or death. Biometrika 46:336-351.

Efron, B., and R. J. Tibshirani. 1993. An introduction to the bootstrap. Monographs on statistics and applied probability, no. 57. Chapman and Hall, London, UK.

Fransson, T. 1998. A feeding experiment on migratory fuelling in Whitethroats, Sylvia communis. Animal Behaviour 55:153-162.

Fransson, T., and T. P. Weber. 1997. Migratory fuelling in Blackcaps (Sylvia atricapilla) under perceived risk of predation. Behavioural Ecology and Sociobiology 41:75-80.

Fuller, M. R., W. S. Seegar, and P. W. Howley. 1995. The use of satellite systems for the study of bird migration. Israel Journal of Zoology 41:243-252.

Glutz von Blotzheim, U., and K. M. Bauer. 1991. Handbuch der Vögel Mitteleuropas. Band 12. Aula-Verlag, Wiesbaden, Germany.

Glutz von Blotzheim, U., and K. M. Bauer. 1997. Handbuch 
der Vögel Mitteleuropas. Band 14. Aula-Verlag, Wiesbaden, Germany.

Gwinner, E. 1990. Circannual rhythms in bird migration: control of temporal patterns and interactions with photoperiod Pages 257-268 in E. Gwinner, editor. Bird migration: the physiology and ecophysiology. Springer, Berlin, Germany.

Hagemeijer, W. J. M., and M. J. Blair. 1997. The EBCC atlas of European breeding birds: their distribution and abundance. Poyser, London, UK.

Hargrove, J. W., and C. H. Borland. 1994. Pooled population parameter estimates from mark-recapture data. Biometrics 50:1129-1141.

Holmgren, N., H. Ellegren, and J. Pettersson. 1993. Stopover length, body mass and fuel deposition rate in autumn migrating adult Dunlins Calidris alpina: evaluating the effects of moulting status and age. Ardea 81:9-20.

Jenni, L., and R. Winkler. 1994. Moult and Ageing of European Passerines. Academic Press, London, UK.

Kaiser, A. 1995. Estimating turnover, movements and capture parameters of resting passerines in standardized capturerecapture studies. Journal of Applied Statistics 22:10391047.

Kendall, W. L., J. D. Nichols, and J. E. Hines. 1997. Estimating temporary emigration using capture-recapture data with Pollock's robust design. Ecology 78:563-578.

Kjellén, N., M. Hake, and T. Alerstam. 1997. Strategies of two Ospreys (Pandion haliaetus) migrating between Sweden and tropical Africa as revealed by satellite tracking. Journal of Avian Biology 28:15-32.

Lavee, D., U. N. Safriel, and I. Meilijson. 1991. For how long do trans-Saharan migrants stop at an oasis? Ornis Scandinavica 22:33-44.

Lebreton, J.-D., K. P. Burnham, J. Clobert, and D. R. Anderson. 1992. Modeling survival and testing biological hypothesis using marked animals: a unified approach with case studies. Ecological Monographs 62:67-118.

Lindström, A., and T. Alerstam. 1992. Optimal fat loads in migrating birds: a test of the time-minimization hypothesis American Naturalist 140:477-491.

Lindström, A., S. Daan, and G. H. Visser. 1994. The conflict between moult and migratory fat deposition: a photoperiodic experiment with Bluethroats. Animal Behaviour 48 : $1173-1181$.

Lyons, J. E., and S. M. Haig. 1995. Fat content and stopover ecology of spring migrant Semipalmated Sandpipers in South Carolina. Condor 97:427-437.

Morris, S. R., D. W. Holmes, and M. E. Richmond. 1996. A ten-year study of the stopover patterns of migratory passerines during fall migration on Appledore Island, Maine. Condor 98:395-409.
Morris, S. R., M. E. Richmond, and D. W. Holmes. 1994 Patterns of stopover by Warblers during spring and fall migration on Appledore Island, Maine. Wilson Bulletin 106:703-718.

Nichols, J. D., and W. L. Kendall. 1995. The use of multistate capture-recapture models to address questions in evolutionary ecology. Journal of Applied Statistics 22:835846.

Pradel, R. 1993. Flexibility in survival analysis from recapture data: handling trap-dependence. Pages 29-37 in J.-D. Lebreton and P. M. North, editors. Marked individuals in the study of bird population. Birkhäuser, Basel, Switzerland.

Pradel, R. 1996. Utilization of capture-mark-recapture for the study of recruitment and population growth rate. Biometrics 52:703-709.

Pradel, R., J. E. Hines, J.-D. Lebreton, and J. D. Nichols. 1997a. Capture-recapture survival models taking account of transients. Biometrics 53:60-72.

Pradel, R., N. Rioux, A. Tamisier, and J.-D. Lebreton. $1997 b$. Individual turnover among wintering Teal in Camargue: a mark-recapture study. Journal of Wildlife Management 61: 816-821.

Reboulet, A.-M., A. Viallefont, R. Pradel, and J.-D. Lebreton. 1999. Selection of survival and recruitment models with SURGE 5.0. Bird Study 46(supplement):148-156.

Richardson, W. J. 1990. Timing of bird migration in relation to weather: updated review. Pages 78-101 in E. Gwinner, editor. Bird migration: the physiology and ecophysiology. Springer, Berlin, Germany.

Schaub, M., and L. Jenni. 2000. Fuel deposition of three passerine bird species along the migration route. Oecologia 122:306-317.

Schaub, M., R. Schwilch, and L. Jenni. 1999. Does tapeluring of migrating Eurasian Reed Warblers increase number of recruits or capture probability? Auk 116:1047-1053.

Seber, G. A. F. 1982. The estimation of animal abundance and related parameters. Second edition. Macmillan, New York, New York, USA.

Shreffler, D. K., C. A. Simenstad, and R. M. Thom. 1990 Temporary residence by juvenile salmon in a restored estuarine wetland. Canadian Journal of Fish and Aquatic Science 47:2079-2084

Weber, T. P., B. J. Ens, and A. I. Houston. 1998. Optimal avian migration: a dynamic model of fuel stores and site use. Evolutionary Ecology 12:377-401.

Weber, T. P., and A. I. Houston. 1997. Flight costs, flight range and the stopover ecology of migrating birds. Journal of Animal Ecology 66:297-306.

\section{APPENDIX}

Derivation of the expressions for stopover duration before $(\mathrm{Sb})$ and after $(\mathrm{Sa})$ capture may be found online in ESA's Electronic Data Archive: Ecological Archives E082-008-A1.

\section{SUPPLEMENTARY MATERIAL}

A 10000 -iteration compiled version of the MATLAB program SODA may be found online in ESA's Electronic Data Archive: Ecological Archives E082-008-S1. 